\title{
Pengaruh kualitas pelayanan terhadap minat menabung nasabah di Bank Syariah Mandiri KCP Dumai Sukajadi
}

\author{
Sandi Andika \\ Sekolah Tinggi Agama Islam Negeri (STAIN) Bengkalis \\ Sandi.andika@gmail.com

\section{Mirza Syahputra} \\ Sekolah Tinggi Agama Islam Negeri (STAIN) Bengkalis \\ mirzaputrabksaja@gmail.com
}

\begin{abstract}
Abstrak Meningkatnya minat menabung nasabah disuatu perbankan syariah tentu juga dipengaruhi oleh kualitas pelayaan yang diberikan oleh pihak bank tersebut walaupun masuh ada faktor lain yang juga mempengaruhinya. Perbankan syariah yang bukan hanya bergerak pada sisi profit oriented saja tentu harus memberikan kualitas pelayanan yang jauh lebih baik agar tingkat kepercayaan nasabah bertambah sehingga akan berbanding lurus dengan minat menabung masyarakat di bank syariah. Bank syariah mandiri sangat konsentrasi dengan pelayanan yang dimana moto dari pelayanan bank yaitu terdepan dan modern, dalam proses transaksinya kepada nasabah untuk menciptakan suasana perbankan yang erat dan bersahabat. Tujuan penelitian ini adalah untuk mengetahui pengaruh kualitas pelayanan Bank Syariah Mandiri Kcp Dumai Sukajadi terhadap minat menabung nasabah, Metode yang digunakan dalam penelitian ini adalah metode Analisis Regresi Linear Sederhana. Uji Koefisien Determinasi (R2), Uji Validitas dan Realibilitas, dan Uji Normalitas serta Uji Hipotesis (UJI T) Berdasarkan uji hipotesis yang dilakukan peneliti, telah diketahui terjadi hubungan positif antara kualitas pelayanan (X) terhadap minat menabung nasabah (Y) sebesar 0,000 < 0,05, sedangkan hasil uji $\mathrm{T}$ menyatakan bahwa nilai thitung lebih besar dari tabel sebesar $(4,775>1,66088)$, dengan signifikan lebih $<0,05$. Maka hipotesis dari penelitian ini yaitu $\mathrm{H}_{\mathrm{o}}$ ditolak $\left(\mathrm{H}_{\mathrm{a}}\right.$ diterima), artinya variabel kualitas pelayanan $(\mathrm{X})$ berpengaruh terhadap minat menabung nasabah (Y) Dengan persentase sumbangan pengaruh variabel independen sebesar $19.2 \%$, sedangkan sisanya sebesar $80.8 \%$ dipengaruhi atau dijelaskan oleh variabel lain yang tidak dimasukkan dalam model penelitian ini
\end{abstract}

Kata Kunci: $\quad$ Kualitas Pelayanan, Nasabah, Persentase, dan Minat Menabung.

\section{PENDAHULUAN}

Kementerian Badan Usaha Milik Negara (BUMN) mencatat dana pihak ketiga (DPK) pada Bank BUMN Syariah semakin meningkat. Artinya, banyak nasabah yang percaya untuk menabung di Bank BUMN Syariah dibandingkan konvesional (Anggraini, 2020). 
Dalam sebuah penelitian yang dilakukan oleh (Cahyadi, 2017) tentang Pengaruh Kualitas Pelayanan Terhadap Minat Menabung Nasabah (Studi Kasus pada Bank Sumsel Babel Cabang Tebing Tinggi) menunjukkan Kualitas Pelayanan berpengaruh positif tetapi tidak terlalu signifikan terhadap Minat Menabung Nasabah. Begitu juga penelitian yang dilakukan oleh (Faqih, 2020) menunjukkan bahwa Kualitas pelayaanan menunjukkan berpengaruh signifikan terhadap minat menabung nasabah pada tabungan marhamah PT Bank Sumut KCP Syariah Karya. selanjutnya penelitian yang dilakukan oleh (Reshita, 2015) menghasilkan bahwa kualitas pelayanan secara simultan memiliki pengaruh yang signifikan terhadap minat menabung nasabah Bank BNI di Sidoarjo.

Kualitas pelayanan konsumen dapat meningkatkan minat menabung ulang nasabah di BNI Syariah Semarang. Nasabah yang memiliki persepsi kualitas yang baik akan terus menabung di BNI Syariah Semarng.Dengan menabung di BNI Syariah Semarang nasabah merasakan tabungannya bebas dari riba dan halal.Namun persepsi kualitas akan memiliki pengaruh yang lebih besar terhadap minat menabung ulang konsumen jika religius satisfaction nasabah terhadap BNI Syariah Semarang baik(Al Kanzu \& Soesanto, 2016)

Proses pelayanan yang diberikan Teller dalam upaya meningkatkan kualitas pelayanan terhadap nasabah di PT Bank Syariah Mandiri Cabang Malang telah sesuai dengan prosedur pelayanan atau aliran jasa yang diberikan kepada nasabah dari kegiatan nasabah menunggu antrian hingga teller menyelesaikan transaksi dengan nasabah (Sri Budi, 2012).

Sehubungan dengan itu menarik untuk melakukan penelitian bagaimana dengan pengaruh kualitas pelayanan terhadap minat menabung Bank Syariah Mandiri KCP Dumai Sukajadi. Apakah kualitas pelayanan berpengaruh signifikan minat menabung atau sebaliknya. Nantinya tentu bisa menjadi salah satu pertimbangan Bank Syariah Mandiri (BSM) dalam upaya meningkatkan minat menabung masyarakat di Kota Dumai .

\section{LANDASAN TEORI}

\section{Bank Syariah}

Perbankan Syariah adalah segala sesuatu yang menyangkut tentang Bank Syariah dan Unit Usaha Syariah, mencakup kelembagaan, kegiatan usaha, serta cara dan proses dalam melaksanakan kegiatan usahanya. Bank Syariah menjalankan kegiatan usahanya berdasarkan Prinsip Syariah dan menurut jenisnya terdiri atas Bank Umum Syariah dan Bank Pembiayaan Rakyat Syariah. (UU No 21 Tahun 2008).

Perbankan syariah merupakan bank yang dalam operasionalnya berdasarkan prinsip-prinsip syariah baik dalam penghimpunan dana dengan prinsip wadi'ah dan mudharabah; dalam pembiayaan menggunakan prinsip jual beli murabahah, salam dan istishna; dalam mengeluarkan produk jasa bank syariah menerapkan prinsip al-wakalah, aIl-hiwalah, al-qardh, al-kafalah dan ar-rahn.(Supriyadi, 2018)

\section{Kualitas Pelayanan}

Kualitas merupakan kesesuaian antara persyaratan dan kecocokan untuk pemakai, perbaikan secara berkelanjutan, terbebas dari kerusakan, untuk memenuhi kebutuhan pelanggan sejak dari awal serta setiap saat, untuk melaksanakan segala sesuatunya secara benar dari awal, dan sesuatu ini dimaksud yang dapat membahagiakan pelanggan. Kualitas berarti menjaga janji kepada pelanggan atas pelayanan yang akan diberikan, sehingga pihakyang dilayani tersebut merasa 
puas dan ini diuntungkan secara tertulis. Kualitas diartikan bahwa: adanya kesesuaian untuk digunakan, atau dapat juga diartikan bahwa kualitas suatu produk pelayanan harus bisa memenuhi apa-apa yang diharapkan oleh penggunaya(Sasmito \& Nabunome, 2018)

Kualitas pelayanan sebagai ukuran seberapa bagus tingkat layanan yang diberikan mampu sesuai dengan harapan pelanggan. Kualitas Pelayanan (service quality) dapat diketahui dengan cara membandingkan persepsi para konsumen atas pelayanan yang nyata-nyata mereka terima/peroleh dengan pelayanan yang sesungguhnya mereka harapkan / inginkan terhadap atribut-atribut pelayanan suatu perusahaan. Jika jasa yang diterima atau dirasakan (perceived service) sesuai dengan yang diharapkan, maka kualitas pelayanan dipersepsikan baik dan memuaskan, jika jasa yang diterima melampaui harapan konsumen, maka kualitas pelayanan dipersepsikan sangat baik dan berkualitas. Sebaliknya jika jasa yang diterima lebih rendah daripada yang diharapkan, maka kualitas pelayanan dipersepsikan buruk (Faqih, 2020)

\section{Minat Menabung}

Minat merupakan perasaan senang dan tertarik pada suatu kegiatan atau obyek, dan kesenangan itu cenderung untuk memperhatikan dan akhirnya aktif berkecimpung dalam kegiatan tersebut. Seseorang yang memiliki minat terhadap suatu aktifitas maka akan memperhatikan secara konsisten dengan perasaan yang senang.(Nisa \& Renata, 2018)

Minat menabung adalah situasi seseorang sebelum melakukan tindakan sebagai respon terhadap keinginan nasabah untuk melakukan pencarian informasi pada produk tertentu atau kecenderungan nasabah untuk memilih suatu produk tabungan yang nasabah rasa cocok sehingga seseorang yang memiliki minat akan memperhatikan produk itu.(Putri et al., 2019)

\section{METODOLOGI PENELITIAN}

Jenis penelitian ini adalah penelitian kuantitatif. Penelitian ini dilakukan di Bank Mandiri Syariah Kcp Dumai Sukajadi Riau pada tahun 2019. Jumlah sampel dalam penelitian ini adalah 98 orang yang merupakan nasabah Bank. Teknik pengumpulan data meliputi kuisioner berupa angket, wawancara dan dokumentasi. Kemudian untuk menganalisa data digunakan uji validitas dan reliabilitas, asumsi klasik, regresi linier sederhana, koefesien determinasi dan uji hipotesis.

\section{HASIL DAN PEMBAHASAN}

Responden dalam penelitian ini adalah Nasabah PT Bank Mandiri Syariah Kantor Cabang Pembantu Dumai Sukajadi. Kuesioner/ Angket yang disebarkan dan dibagikan kepada responden adalah sebanyak 98 lembar/ rangkap yang dberisi butir- butir pertanyaan tentang variabel $\mathrm{X}$ yaitu kualitas pelayanan dan variabel $\mathrm{Y}$ yaitu minat menabung nasabah. Dibawah ini adalah hasil dari analisa frekuensi hasil penelitian ini disajikan sebagai berikut:

Tabel 4.0. Jenis Kelamin

\begin{tabular}{|c|l|r|r|r|r|}
\hline \multicolumn{2}{|c|}{} & Frequency & Percent & Valid Percent & Cumulative Percent \\
\hline \multirow{3}{*}{ Valid } & LAKI LAKI & 47 & 48.0 & 48.0 & 48.0 \\
\cline { 2 - 6 } & PEREMPUAN & 51 & 52.0 & 52.0 & 100.0 \\
\cline { 2 - 6 } & Total & 98 & 100.0 & 100.0 & \\
\hline
\end{tabular}

Data Hasil Olahan Data Primer 
Berdasarkan tabel 4.0 diatas menunjukkan setelah dianalisa frekuensi maka diketahui bahwa jumlah responden sebanyak 98 orang yang dimana terbagi laki laki berjumlah 47 orang dengan persentase $48 \%$ serta perempuan berjumlah 51 orang dengan persentase $52 \&$. dengan jumlah total keseluruhannya 98 orang.

Tabel 4.1. Kelompok Umur

\begin{tabular}{|c|r|r|r|r|r|}
\hline \multicolumn{2}{|c|}{} & Frequency & Percent & Valid Percent & Cumulative Percent \\
\hline \multirow{4}{*}{ Valid } & $20-25$ & 18 & 18.4 & 18.4 & 18.4 \\
\cline { 2 - 6 } & $26-35$ & 27 & 27.6 & 27.6 & 45.9 \\
\cline { 2 - 6 } & $66-45$ & 23 & 23.5 & 23.5 & 69.4 \\
\cline { 2 - 6 } & $46-55$ & 15 & 15.3 & 15.3 & 84.7 \\
\cline { 2 - 6 } & $56-65$ & 15 & 15.3 & 15.3 & 100.0 \\
\cline { 2 - 6 } & Total & 98 & 100.0 & 100.0 & \\
\hline
\end{tabular}

\section{Data Hasil Olahan Data Primer}

Berdasarkan tabel 4.1 diatas menunjukkan setelah dianalisa frekuensi maka diketahui bahwa jumlah responden yang berdasarkan kelompok umurnya yaitu 20-25 sebanyak 18 orang dengan persentase $18.4 \%$, 26-35 sebanyak 27 orang dengan persentase sebesar $27.6 \%, 36-45$ sebanyak 23 orang dengan persentase sebesar $23.5 \%$, 46-55 sebanyak 15 dengan persentase sebesar $15.3 \%$, serta 56-65 sebanyak 15 orang dengan persentase $15.3 \%$. dengan total keseluruhan 98 orang responden didalam penelitian ini.

\section{Uji Validitas}

Tabel 4.2. Uji Validitas Varibel $X$

\begin{tabular}{|c|c|c|c|c|}
\hline Variable & Item & r Hitung & r Tabel & Keterangan \\
\hline \multirow{4}{*}{ X } & P1 & 0,559 & 0,198 & Valid \\
\cline { 2 - 5 } & P2 & 0,579 & 0,198 & Valid \\
\cline { 2 - 5 } & P3 & 0,611 & 0,198 & Valid \\
\cline { 2 - 5 } & P4 & 0,643 & 0,198 & Valid \\
\cline { 2 - 5 } & P5 & 0,615 & 0,198 & Valid \\
\cline { 2 - 5 } & P6 & 0,615 & 0,198 & Valid \\
\hline
\end{tabular}

Data Hasil Olahan Data Primer

Berdasarkan tabel diatas menunjukkan bahwa seluruh item pernyataan variabel kualitas pelayanan (X) mempunyai nilai kolerasi (r) yang lebih besar dari $r$ tabel yaitu 0,198 yang artinya semua butir pernyataan dapat dikatakan valid dan dapat digunakan sebagai instrumen penelitian

Tabel 4.3. Uji Validitas Varibel Y

\begin{tabular}{|c|c|c|c|c|}
\hline Variable & Item & r Hitung & r Tabel & Keterangan \\
\hline \multirow{4}{*}{ Y } & P1 & 0,563 & 0,198 & Valid \\
\cline { 2 - 5 } & P2 & 0,570 & 0,198 & Valid \\
\cline { 2 - 5 } & P3 & 0,566 & 0,198 & Valid \\
\cline { 2 - 5 } & P4 & 0,507 & 0,198 & Valid \\
\cline { 2 - 5 } & P5 & 0,446 & 0,198 & Valid \\
\cline { 2 - 5 } & P6 & 0,517 & 0,198 & Valid \\
\hline
\end{tabular}

Data Hasil Olahan Data Primer 
Berdasarkan tabel diatas menunjukkan bahwa seluruh item pernyataan variabel minat menabung nasabah ( $\mathrm{Y}$ ) mempunyai nilai kolerasi (r) yang lebih besar dari $\mathrm{r}$ tabel yaitu 0,198 yang artinya semua butir pernyataan dapat dikatakan valid dan dapat digunakan sebagai instrumen penelitian.

\section{Uji Reliabilitas}

Tabel 4.4. Uji Reabilitas

\begin{tabular}{|c|c|c|c|}
\hline \multirow{2}{*}{ Variabel } & \multicolumn{2}{|c|}{ Hasil Reabilitas (Alpha) } & \multirow{2}{*}{ Keterangan } \\
\cline { 2 - 3 } & Kriteria & $\begin{array}{c}\text { Cronbach's } \\
\text { Alpha }\end{array}$ & \\
\hline $\mathrm{X}$ & 0,60 & 0,651 & Reliabel \\
\hline $\mathrm{Y}$ & 0,60 & 0,692 & Reliabel \\
\hline
\end{tabular}

Data Hasil Olahan Data Primer

Dari hasil tabel 4.4 bahwa hasil uji reabilitas yang dilihat dari crobach's alpa untuk variabel X dan Y, yang diperoleh sebesar 0,651 dan 0,692 lebih besar dari 0,60 artinya data tersebut sudah reliable, dan layak untuk digunakan.

\section{Uji Normalitas}

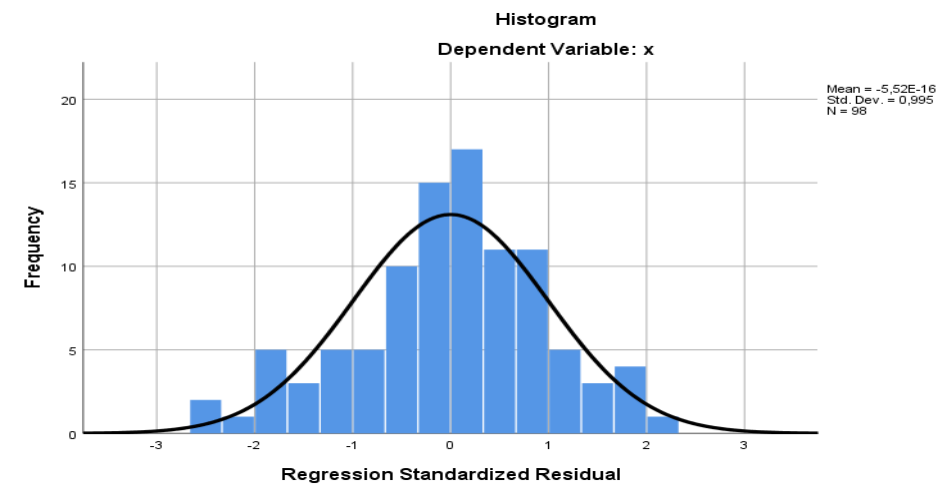

Grafik 4.1, Grafik Histogram

Berdasarkan grafik histogram menunjukkan pola distribusi normal maka regresi memenuhi asumsi normalitas.

Tabel 4.5. Uji Kolmogrov-Smirnov

\begin{tabular}{|l|l|r|}
\hline \multicolumn{2}{|l|}{} & Unstandardized Residual \\
\hline \multirow{2}{*}{ Normal Parameters ${ }^{\mathrm{a}, \mathrm{b}}$} & Mean & 98 \\
\cline { 2 - 3 } & Std. Deviation & $0 \mathrm{E}-7$ \\
\hline \multirow{3}{*}{ Most Extreme Differences } & Absolute & .71700289 \\
\cline { 2 - 3 } & Positive & .076 \\
\cline { 2 - 3 } & Negative & .050 \\
\hline Kolmogorov-Smirnov Z & -.076 \\
\hline Asymp. Sig. (2-tailed) & .754 \\
\hline \multicolumn{2}{|l|}{ a. Test distribution is Normal. } \\
\hline \multicolumn{2}{|l|}{ b. Calculated from data. } \\
\hline
\end{tabular}


Jurnal Ekonomi \& Ekonomi Syariah Vol 4 No 2, Juni 2021

E-ISSN : 2599-3410 | P-ISSN : 2614-3259

DOI : https://doi.org/10.36778/jesya.v4i2.451

Dari hasil uji normalitas pada tabel one-sampel kolmogrov-smirnov test bahwa nilai signifikan data untuk kualitas pelayanan dan minat menabung nasabah adalah 0,620 maka lebih besar dari 0,05 sehingga data tersebut berdistribusi normal.

\section{Model Persamaan Regresi Linier Sederhana}

Tabel 4.6. Uji Regresi Linier Sederhana

\begin{tabular}{|c|c|c|c|c|c|c|}
\hline & \multirow[t]{2}{*}{ Model } & \multicolumn{2}{|c|}{$\begin{array}{c}\text { Unstandardized } \\
\text { Coefficients }\end{array}$} & \multirow{2}{*}{$\begin{array}{c}\text { Standardized } \\
\text { Coefficients } \\
\text { Beta }\end{array}$} & \multirow[t]{2}{*}{$\mathrm{T}$} & \multirow[t]{2}{*}{ Sig. } \\
\hline & & B & Std. Error & & & \\
\hline \multirow{2}{*}{1} & (Constant) & 13.736 & 2.352 & & 5.841 & .000 \\
\hline & Kualitas Pelayanan & .410 & .086 & .438 & 4.775 & .000 \\
\hline
\end{tabular}

Berdasarkan Tabel 4.6 di atas dapat dirumuskan suatu persamaan regresi sebagai berikut:

$$
\begin{gathered}
Y=a+b x \\
Y=13,736+0,410 X
\end{gathered}
$$

Dimana:

$Y=$ Variable dependen (Minat Menabung)

$a=$ Konstanta

$b=$ Koefisien regresi

$x=$ Variable independen (Kualitas Pelayanan)

Berdasarkan hasil persamaan regresi sederhana menunjukkan bahwa :

1) $\mathrm{a}=$ angka konstan dari Unstandardized Coefficients memiliki nilai sebesar 13,736. Angka ini merupakan angka konstan yang mempunyai arti bahwa jika tidak ada kualitas pelayanan (X) maka nilai konsisten minat menabung (Y) sebesar 13,736.

2) $\quad b=$ Koefisien regresi $X$ sebesar 0,410 menyatakan bahwa setiap penambahan 1 nilai kualitas pelayanan $(\mathrm{X})$ maka minat menabung $(\mathrm{Y})$ akan mengalami kenaikan sebesar $13,736$.

3) Nilai koefisien regresi bernilai (+), maka dengan demikian dapat dikatakan bahwa kualitas pelayanan berpengaruh positif terhadap minat menabung nasabah

\section{Uji Hipotesis}

Tabel 4.7. Uji Hipotesis

\begin{tabular}{|c|l|r|r|r|r|r|}
\hline \multirow{2}{*}{\multicolumn{2}{|c|}{ Model }} & \multicolumn{2}{|c|}{$\begin{array}{c}\text { Unstandardized } \\
\text { Coefficients }\end{array}$} & $\begin{array}{c}\text { Standardized } \\
\text { Coefficients }\end{array}$ & \multirow{2}{*}{ T } & \multirow{2}{*}{ Sig. } \\
\cline { 3 - 6 } \multicolumn{2}{|c|}{} & \multicolumn{1}{|c|}{ B } & Std. Error & \multicolumn{1}{|c|}{ Beta } & & \\
\hline \multirow{2}{*}{1} & (Constant) & 13.736 & 2.352 & & 5.841 & .000 \\
\cline { 2 - 7 } & Kualitas Pelayanan & .410 & .086 & .438 & 4.775 & .000 \\
\hline
\end{tabular}

a. Dependent Variable: MInat Menabung

Berdasarkan output diatas, pengujian hipotesis dalam penelitian ini dapat dijabarkan sebagai berikut dengan nilai $\mathrm{T}$ tabel pada taraf signifikansi 5\% dan df (derajat kebebasan) atau $\mathrm{T}$ tabel $\mathrm{n}-\mathrm{k}-1=96$ adalah 1,66088. Diketahui t hitung $(4.775)>\mathrm{t}$ tabel $(1,66088)$ dengan signifikan $(0,000)<(0,05)$. Maka dapat diartikan bahwa hipotesis penelitian ini adalah $\mathrm{H}_{\mathrm{o}}$ ditolak dan $\mathrm{H}_{\mathrm{a}}$ diterima, dimana variabel kualitas pelayanan $(\mathrm{X})$ berpengaruh terhadap minat menabung nasabah (Y). 
Jurnal Ekonomi \& Ekonomi Syariah Vol 4 No 2, Juni 2021

E-ISSN : 2599-3410 | P-ISSN : 2614-3259

DOI : https://doi.org/10.36778/jesya.v4i2.451

\section{Uji Determinasi}

Tabel 4.8. Nilai Koefisien Determinasi Model Summary ${ }^{b}$

\begin{tabular}{|r|r|rr|}
\hline R Square & $\begin{array}{c}\text { Adjusted R } \\
\text { Square }\end{array}$ & \multicolumn{2}{|c|}{ Std. Error of the Estimate } \\
\hline .192 & .184 & & 1.614 \\
\hline
\end{tabular}

a. Predictors: (Constant), Kualitas Pelayanan

b. Dependent Variable: MInat Menabung

Nilai $\mathrm{R}$ adalah sebesar 0,438 sama dengan 43,8 \% yang menunjukkan bahwa pengaruh kualitas pelayanan (X) terhadap minat menabung (Y) pengaruhnya cukup erat sebesar 43,8 \%. Nilai Adjusted R Square sebesar 0,192 berarti 19,2\% minat menabung (Y) dapat dijelaskan oleh kualitas pelayanan. Sedangkan sisanya $80,8 \%$ dapat dijelaskan oleh faktor-faktor lain yang tidak diteliti dalam penelitian ini. Standard Error of Estimate artinya mengukur variasi dari nilai yang diprediksi. Nilai Standard Error of Estimatenya 1,614 Semakin kecil Standard Error of Estimatenya berarti model semakin baik.

\section{KESIMPULAN}

Kesimpulan dari penelitian ini adalah berdasarkan uji hipotesis yang dilakukan peneliti, telah diketahui terjadi hubungan positif antara kualitas pelayanan (X) terhadap peningkatan minat menabung nasabah (Y) sebesar 0,000 <0,05, sedangkan hasil uji T menyatakan bahwa nilai thitung lebih besar dari $t_{\text {tabel }}$ sebesar $(4,775>1,66088)$, dengan signifikan lebih < 0,05. Maka hipotesis dari penelitian ini yaitu $\mathrm{H}_{\mathrm{o}}$ ditolak $\left(\mathrm{H}_{\mathrm{a}}\right.$ diterima), artinya variabel kualitas pelayanan (X) berpengaruh terhadap peningkatan minat menabung nasabah (Y) Dengan persentase sumbangan pengaruh variabel independen sebesar 19.2\%, sedangkan sisanya sebesar $80.8 \%$ dipengaruhi atau dijelaskan oleh variabel lain yang tidak dimasukkan dalam model penelitian ini.

\section{DAFTAR PUSTAKA}

Al Kanzu, H., \& Soesanto, H. (2016). ANALISIS PENGARUH PERSEPSI KUALITAS PELAYANAN DAN PERCEIVED VALUE TERHADAP KEPUASAN RELIGIUS UNTUK MENINGKATKAN MINAT MENABUNG ULANG (Studi Pada BNI Syariah Semarang). Jurnal Studi Manajemen Organisasi, 13(1), 14. https://doi.org/10.14710/jsmo.v13i1.13410

Anggraini, R. (2020, December 9). Minat menabung di Bank BUMN Syariah meningkat 2 kali lipat. https://economy.okezone.com/read/2020/12/09/320/2324730/minat-menabung-dibank-bumn-syariah-meningkat-2-kali-lipat

Cahyadi. (2017). PENGARUH KUALITAS PELAYANAN TERHADAP MINAT MENABUNG NASABAH ( Studi Kasus pada Bank Sumsel Babel Cabang Tebing Tinggi ) Program Studi Manajemen STIE Musi Rawas, Lubuklinggau Email : Ari_Cahyadi@muralinggau.ac.id. 22(3), 53-65.

Faqih, F. Al. (2020). Pengaruh Kualitas Pelayanan Dan Bagi Hasil Terhadap Minat Menabung 


\section{JESYA}

JURNAL EKONOMI \& EKONOMI SYARIAH

Jurnal Ekonomi \& Ekonomi Syariah Vol 4 No 2, Juni 2021

E-ISSN : 2599-3410 | P-ISSN : 2614-3259

DOI : https://doi.org/10.36778/jesya.v4i2.451

Nasabah Pada Tabungan Marhamah Pt Bank Sumut Kcp Syariah Karya. Al-Infaq: Jurnal Ekonomi Islam, 11(1), 22. https://doi.org/10.32507/ajei.v11i1.506

Nisa, A., \& Renata, D. (2018). Analisis Minat Belajar Siswa dan Implikasinya Terhadap Layanan Bimbingan dan Konseling. KONSELI: Jurnal Bimbingan Dan Konseling ( $E$ Journal), 5(2), 119. https://doi.org/10.24042/kons.v5i2.3058

Putri, Y., Solihat, A., Rahmayani, R., Iskandar, I., \& Trijumansyah, A. (2019). Strategi meningkatkan Minat Menabung di Bank Syariah melalui Penerapan Religiusitas. Jurnal Manajemen Dan Bisnis Performa, 16(1), 77-88. https://doi.org/10.29313/performa.v16i1.4532

Reshita, R. M. (2015). Pengaruh Promosi, Lokasi, Dan Kualitas Pelayanan Terhadap Minat Menabung Nasabah Di Bank Bni Di Sidoarjo [Stie Perbanas Surabaya]. http://eprints.perbanas.ac.id/id/eprint/834

Sasmito, C., \& Nabunome, A. (2018). Analisis Kualitas Pelayanan Publik (Studi Kepuasan Pelanggan Pada Pln-Rayon Soe Di Wilayah Kerja Puskesmas Tobu, Kabupaten Timor Tengah Selatan). Reformasi, 8(2), 136. https://doi.org/10.33366/rfr.v8i2.1100

Supriyadi, A. (2018). Bank Syariah Dalam Perspektif Filosofis, Yuridis Dan Sosiologis Bangsa Indonesia. MALIA: Journal of Islamic Banking and Finance, 1(1), 1-14. https://doi.org/10.21043/malia.v1i1.3980

Undang Undang Republik Indonesia No 21 Tahun 2008 Tentang Perbankan Syariah 